\title{
Multicenter Experience with FRED Jr Flow Re-Direction Endoluminal Device for Intracranial Aneurysms in Small Arteries
}

(D) M.A. Möhlenbruch, (D) Kizilkilic, (D) M. Killer-Oberpfalzer, (D) F. Baltacioglu, (D). Islak, DM. Bendszus, (D) S. Cekirge, DI. Saatci, and (i) N. Kocer

\begin{abstract}
BACKGROUND AND PURPOSE: Flow diverters are emerging as an endovascular treatment alternative for proximally located intracranial aneurysms. However, treatment of aneurysms at and beyond the circle of Willis is not well-established. We assessed the clinical safety and efficacy of the Flow Re-Direction Endoluminal Device Jr (FRED Jr) dedicated to small-vessel diameters between 2.0 and $3.0 \mathrm{~mm}$.
\end{abstract}

MATERIALS AND METHODS: This was a multicenter observational clinical study of 42 patients with 47 aneurysms treated by a flowdirection technique with the FRED Jr. The primary end point for clinical safety was the absence of death, major or minor stroke, and TIA. The primary end point for treatment efficacy was complete and near-complete occlusion according to the O'Kelly-Marotta grading scale at follow-up after 1, 6, and 12 months.

RESULTS: The FRED Jr deployment was technically successful in all cases. In 39/42 (93\%) patients, the primary safety end point was reached; in the 3 remaining patients, 1 disabling ischemic stroke, 1 minor stroke with complete recovery at discharge, and 1 TIA were observed. Two asymptomatic, completely reversible side-branch occlusions occurred. Angiographic (DSA or flat panel CT) and clinical follow-up were available after 1 month in $41 / 47$ (87\%), 6 months in $27 / 47$ (57\%), and 12 months in 11/47 (23\%) aneurysms. The primary efficacy end point was reached at 1 month in $27 / 41$ (66\%), at 6 months in $21 / 27$ (78\%), and at 12 months in $11 / 11(100 \%)$ aneurysms.

CONCLUSIONS: Deployment of the FRED Jr is safe and effective in the treatment of intracranial aneurysms located in small vessels.

ABBREVIATIONS: $\mathrm{ACA}=$ anterior cerebral artery; AcomA $=$ anterior communicating artery; FPCT $=$ flat panel CT; FRED Jr $=$ Flow Re-Direction Endoluminal Device Jr; OKM = O'Kelly-Marotta grading scale

$\mathbf{T}$ he application of flow diversion with different flow-diverter stents for the treatment of intracranial aneurysms has gained increasing acceptance during the past several years. ${ }^{1}$ A braided nitinol mesh with $30 \%-40 \%$ metal-covered surface area is the mainstay of the stent design. Expansion of the flow diverter at the

Received February 24, 2017; accepted after revision May 24.

From the Department of Neuroradiology (M.A.M., M.B.), Heidelberg University Hospital, Heidelberg, Germany; Department of Neuroradiology (O.K., C.I., N.K.), Cerrahpasa Medical Faculty, Istanbul University, Istanbul, Turkey; Department of Neurology/Research Institute of Neurointervention (M.K.-O.), Paracelsus Medical University, Salzburg, Austria; Department of Radiology (F.B.), Marmara University School of Medicine, Istanbul, Turkey; Department of Radiology (S.C.), Koru and Bayindir Hospital, Ankara, Turkey; and Department of Radiology (S.C., I.S.), Yüksek Ihtisas University, Koru Hospital, Ankara, Turkey.

Paper previously presented, in part, at: Seminar of the Anatomy Biology Clinical Correlations - Working group in Interventional Neuroradiology, January 15-20, 2017; Val d'Isère, France.

Please address correspondence to Markus A. Möhlenbruch, MD, Department of Neuroradiology, Heidelberg University Hospital, Im Neuenheimer Feld 400, 69120 Heidelberg, Germany; e-mail: markus.moehlenbruch@med.uni-heidelberg.de

三 Indicates article with supplemental on-line appendix and tables.

http://dx.doi.org/10.3174/ajnr.A5332 aneurysm base notably decreases flow and subsequently induces thrombosis. The blood, diverted from the aneurysm sac, continues to flow through the porous mesh of the flow diverter following the pressure difference from the parent vessel to smaller branches. ${ }^{2,3}$ Due to its singular design, a metal-covered inner stent layer with low permeability and an outer, more porous and stable stent scaffold, the Flow Re-Direction Endoluminal Device (FRED; MicroVention, Tustin, California) may be superior to other flow diverters, providing safer delivery and more effective occlusion of the aneurysm. ${ }^{4-9}$ The FRED Jr (MicroVention) has a similar dual-layer design and is the first flow diverter dedicated to small vessels (ie, $\leq 3 \mathrm{~mm}$ ). In the past, the flow diverter was not widely used in the treatment of distal circulation aneurysms due to their relatively superficial anatomy and good accessibility for microsurgical clipping. Furthermore, the delivery of the device into the relatively small-caliber vessels of the distal circulation was considered technically difficult. ${ }^{10}$ However, clinical experience with such potential complications has rarely been reported. ${ }^{11-16}$ Here, we report on our multicenter experience of the FRED Jr 
flow diverter endovascular treatment of aneurysms in small cerebral vessels and present the feasibility, safety, and effectiveness of this treatment.

\section{MATERIALS AND METHODS Patient Selection}

Local ethics committees approved this observational study, and informed consent was obtained from all subjects before treatment and chart review. The clinical and radiologic records of all consecutive subjects enrolled in a prospective registry of subjects treated with the FRED Jr at 6 centers (On-line Appendix) between October 2015 and December 2016 were reviewed retrospectively. Two operators (M.A.M. and N.K.) gathered and analyzed the data independently. Data collection included demographics; aneurysm features, including type, size, and location; vessel diameter and angulation; details of the endovascular treatment; clinical presentation; follow-up imaging; and clinical outcome. A multidisciplinary team (vascular neurosurgeons, interventional neuroradiologists) made treatment decisions on a case-by-case basis. The only inclusion criterion for treatment with the FRED Jr was an intracranial aneurysm located on a parent vessel with a 3-mm diameter.

\section{Antiplatelet Therapy}

In 4 centers (Cerrahpasa Medical Faculty, Heidelberg University Hospital, Marmara University School of Medicine, Paracelsus Medical University), the standard antiplatelet therapy included daily dual antiplatelet medication with 100-300 mg of aspirin and $75 \mathrm{mg}$ of clopidogrel (loading dose, $300 \mathrm{mg}$ ), starting no less than 5 days before the procedure and maintaining the therapy for a minimum of 3-6 months after the procedure. After 3-6 months, the patients were switched to aspirin only for a minimum of 6 months or for life. In 2 centers (Yüksek Ihtisas University, Koru and Bayindir Hospital), a daily mono-antiplatelet medication was initiated with prasugrel, $10 \mathrm{mg}$ (loading dose $40 \mathrm{mg}$ ), for 6 months and continued with aspirin thereafter. This regimen was also used in the first 4 centers in case of clopidogrel nonresponse. Platelet inhibition was tested with different methods, such as VerifyNow (Accumetrics, San Diego, California) or light transmission aggregometry either 1 day or immediately before endovascular treatment. Concurrent with the procedure, a bolus of standard heparin (70-100 IU/kg) initiated anticoagulation, which was maintained through intravenous administration to sustain an activated clotting time of 250-300 seconds or 2-2.5 times that of baseline.

\section{FRED J}

The FRED Jr flow diverter was designed to treat aneurysms located in small intracranial vessels. This stent comprises 2 integrated nitinol braided inner and outer layers. The inner layer is of lower porosity, braided in a 36-wire format; and the outer stent layer is of higher porosity, braided in a 16-wire format. This duallayer design encompasses approximately $90 \%$ of its total length, with single-layer flares (part of the outer layer) at each end. These flares, 4 at each end of the stent, are assembled with platinum markers for radiopacity. Two interwoven tantalum wires integrate both layers and provide radiopaque visibility along the duallayer length of the stent. The FRED Jr is currently recommended for vessel diameters from 2.0 to $3.0 \mathrm{~mm}$. Available FRED Jr sizes are 2.5- and 3.0-mm diameters with working lengths (dual-layer coverage) between 8 and $37 \mathrm{~mm}$. The stainless steel delivery microwire has a radiopaque tip and is shortened to reside only within the proximal portion of the FRED Jr device during deployment. As long as the flared ends and a minimal portion of the proximal working length remain within the 0.021 -inch delivery microcatheter (Headway 21, MicroVention), the Fred Jr pusher allows resheathing and the device can be repositioned to optimize the position across the aneurysm neck. As soon as the total length of the stent is released from the microcatheter, it fully expands to its final deployed position.

\section{Description of Technique}

All patients were treated under general anesthesia via a transfemoral approach. Through a femoral sheath, a $6 \mathrm{~F}-8 \mathrm{~F}$ guiding catheter was advanced into the carotid or vertebral artery. Next, the target vessel was analyzed via biplane angiography and $3 \mathrm{D}$ rotational angiography. On the basis of the observed length of the aneurysm neck, a flow diverter was chosen with the aim of ensuring arterial wall coverage and an overlap of the inner mesh of at least $2 \mathrm{~mm}$ beyond the proximal and distal margins of the aneurysm neck. With a standard microguidewire, a Headway 21 microcatheter was maneuvered beyond the aneurysm neck. Then the flow diverter was unsheathed under roadmap guidance. This was achieved through slow withdrawal of the delivery microcatheter while, at the same time, holding or gently pushing the delivery wire to achieve complete expansion and wall apposition of the flow diverter for 2-3 minutes. In cases of incomplete opening, seen on $2 \mathrm{D}$ or $3 \mathrm{D}$ angiography, an in-stent percutaneous transluminal angioplasty with a balloon microcatheter was implemented. If additional aneurysm coiling was required to achieve aneurysm occlusion, the initially used microcatheter was jailed between the parent vessel wall and the flow diverter at its deployment.

\section{Evaluation of End Points}

Safety. Clinical evaluation was performed by a board-certified neuroradiologist, neurosurgeon, or neurologist immediately postprocedure, at 2 hours after the procedure, on the following day, and at discharge. Patient outcomes were assessed with the modified Rankin Scale. The primary end point for clinical safety was the absence of mortality, stroke (major or minor), and TIA. Technical safety was assessed by the attending neurointerventionalist on conventional DSA and, in some cases, additionally with 3D-DSA and/or flat panel CT (FPCT). Technical safety features of the flow diverter included navigation, radiopacity, deployment, expansion, and vessel wall apposition.

Efficacy. Treatment results were graded according to the O'Kelly-Marotta (OKM) grading scale for assessment of cerebral aneurysms treated by flow diversion. ${ }^{17}$ The initial occlusion grade was composed of the initial degree of filling ( $\mathrm{A}=$ total, $\mathrm{B}=$ subtotal, $\mathrm{C}=$ entry remnant, $\mathrm{D}=$ no filling) and the degree of stasis (prolongation of stasis into $1=$ arterial, $2=$ capillary, $3=$ venous phase). On follow-up examinations, only the degree of filling was rated with digital subtraction angiography or FPCT according to 


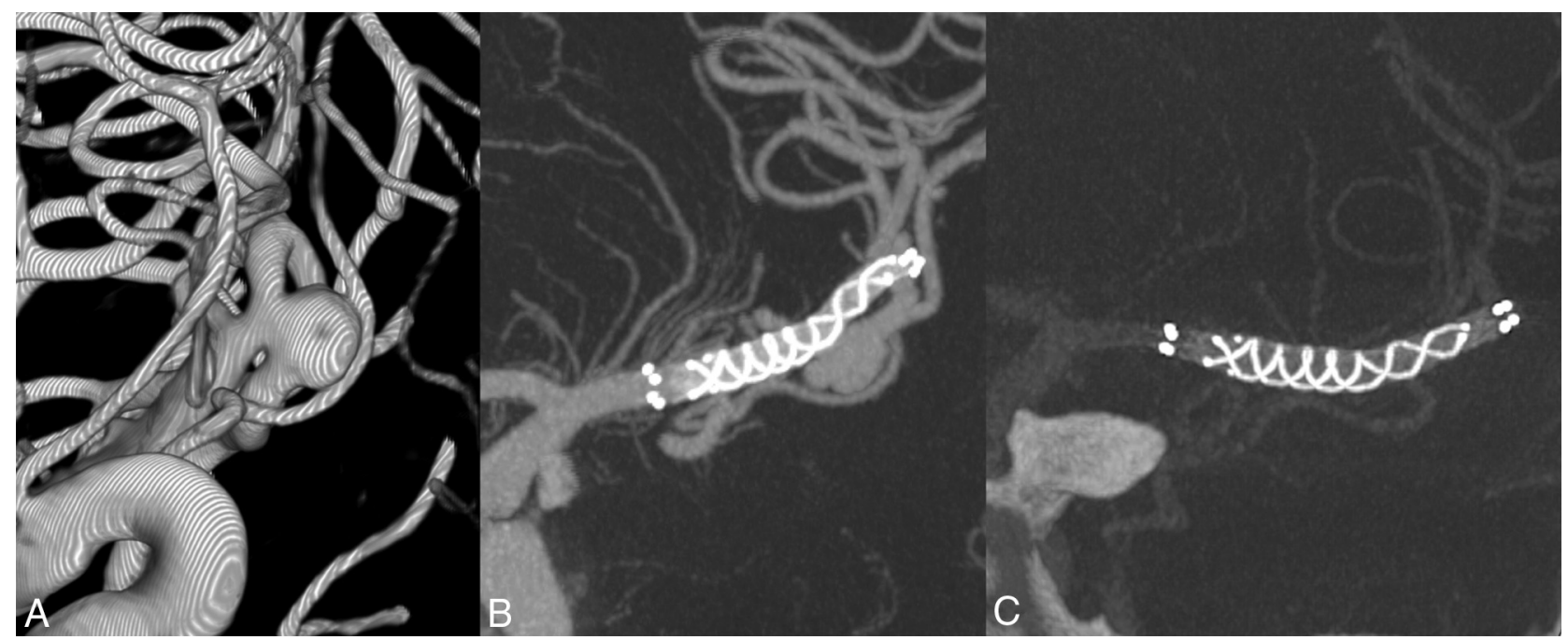

FIG 1. Patient 6 with a bifurcation aneurysm of the middle cerebral artery (3D-DSA, $A$ ) and after implantation of a FRED Jr in the Ml and superior MCA trunk (arterial FPCT, B). At 3-month follow-up, complete occlusion was observed (venous FPCT, $C$ ).
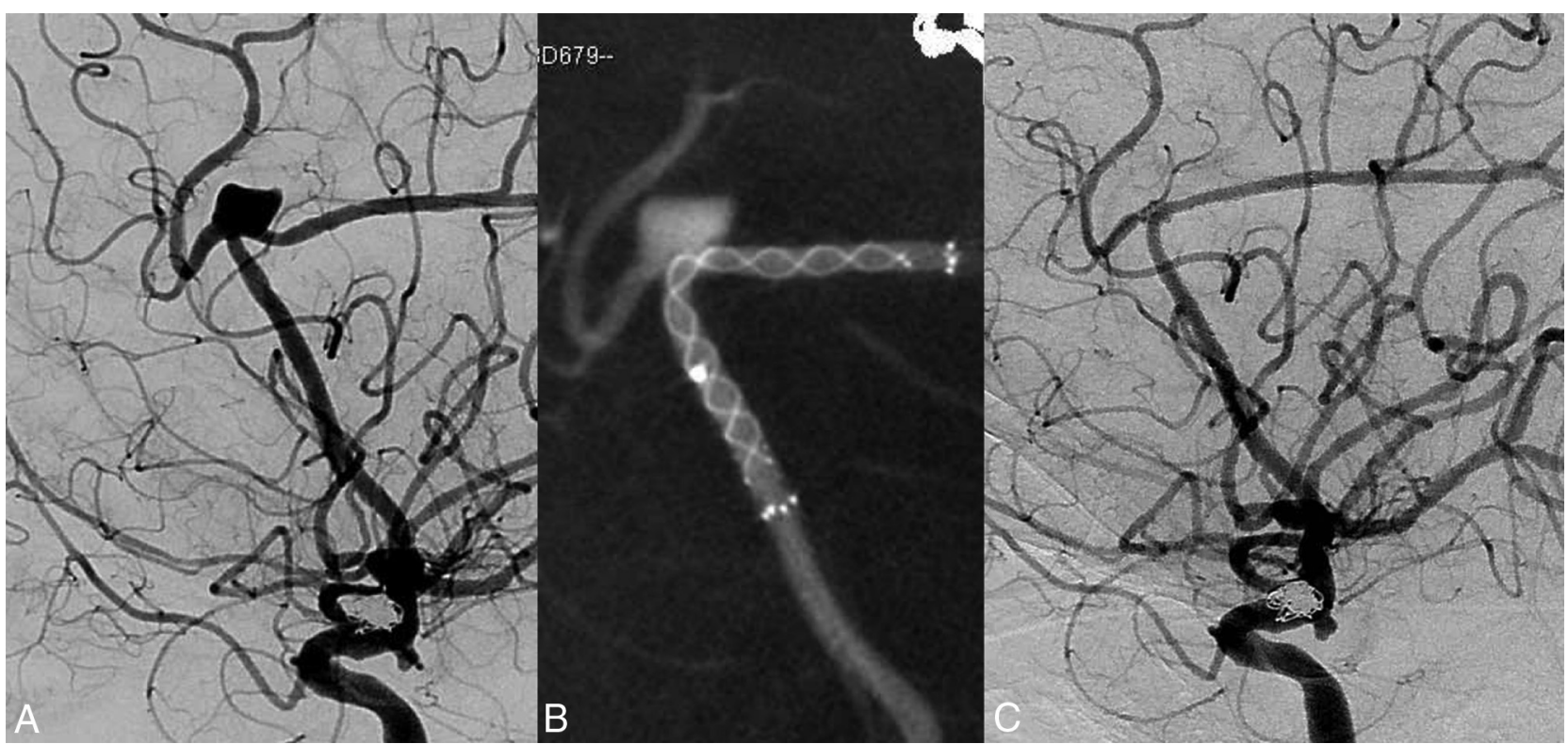

FIG 2. Patient 23 with an $A 2 / A 3$ aneurysm of the anterior cerebral artery (A), and after deployment of a FRED Jr (B). At 6-month follow-up, complete occlusion was observed (C).

the OKM scale for comparison with the immediate results. The primary end point for treatment efficacy was complete and nearcomplete occlusion (ie, OKM C and D) at follow-up after 1, 6, and 12 months.

\section{Statistics}

Differences in variable distribution between groups were compared using Kruskal-Wallis tests for continuous variables and $\chi^{2}$ tests for categoric variables. Significant results on univariate analysis were included in an ordered categoric regression model to measure their combined effect. All statistical analysis was undertaken with SPSS, Version 22.0 (IBM, Armonk, New York).

\section{RESULTS}

\section{Baseline Patient and Aneurysm Characteristics}

Forty-two patients (26 female; median age, 53 years; age range, 15-80 years) with 47 aneurysms were included. Demographics of all enrolled patients and features of the treated aneurysms are shown in the On-line Table 1. On-line Table 2 lists clinical details and angiographic imaging features. Representative cases are presented in Figs 1-3.

Eighteen aneurysms originated from the middle cerebral artery; 13, from the anterior cerebral artery (ACA) distal to anterior communicating artery (AcomA); 11, from the AcomA or A1/A2 junction of the ACA; 2 , from the posterior cerebral artery; 1 , from the superior cerebellar artery; and 1, from the vertebral artery at the V4 level. One was located at the tip of the terminal segment of the ICA. We included 35 saccular aneurysms, 9 fusiform/ dissecting aneurysms, and 2 giant aneurysms (including 1 partially thrombosed aneurysm) and 1 blisterlike aneurysm. One aneurysm was symptomatic with a neurologic deficit, and 1 aneurysm was in the subacute stage after SAH.

The target lesion had been previously treated in 11 patients:

AJNR Am J Neuroradiol 38:1959-65 Oct 2017 www.ajnr.org

1961 


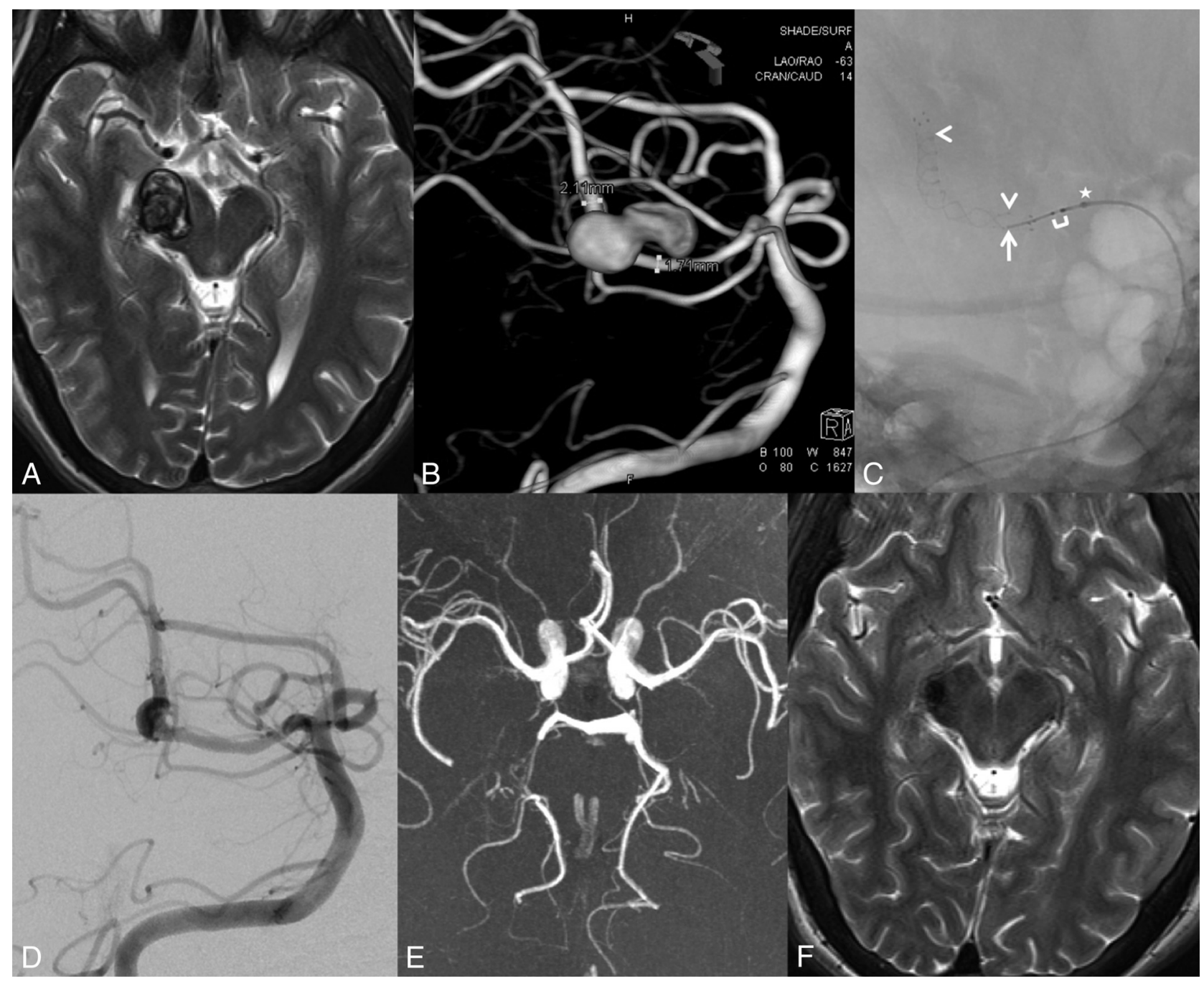

FIG 3. Patient 35 with a partially thrombosed giant aneurysm originating from the posterior cerebellar artery (T2, A; 3D-DSA, B). After deployment of a FRED Jr (arrowheads indicating the flow-diverting working zone, arrow pointing to the tip of the delivery wire, bracket showing the delivery wire markers where normally the proximal stent markers are compressed within the microcatheter, asterisk indicating the tip of the microcatheter; $C$ ), the aneurysm filling is reduced $(D)$. At 12-month follow-up, the aneurysm is almost completely shrunken (TOF E; T2, F).

Five aneurysms had been coiled previously and developed a reperfusion. Two aneurysms were treated with flow diverters (the superior cerebellar artery with the Pipeline Embolization Device, Covidien, Irvine, California; and A2 with the Silk flow diverter, Balt Extrusion, Montmorency, France), but the aneurysms did not occlude during follow-up. Additionally, 4 aneurysms had regrowth after initial clipping.

\section{Technical Results}

The FRED Jr could always (all patients, all aneurysms) be successfully maneuvered to the target area and deployed across the aneurysm base to achieve complete coverage. However, in 2 cases (AcomA and A1/A2 junction), a longer version of the FRED Jr than initially chosen was implanted to ensure complete neck coverage. A single flow diverter was sufficient to treat the aneurysm in all cases.

The median aneurysm diameter was $6 \mathrm{~mm}$ (range, 1.3-25.2 $\mathrm{mm}$ ) with a median neck size of $4 \mathrm{~mm}$ (range, 1.3-14.5 $\mathrm{mm}$ ). The stented parent vessels had a median diameter of $2.4 \mathrm{~mm}$ (range,
$1.4-3.6 \mathrm{~mm}$ ) proximally and $2.1 \mathrm{~mm}$ (range, $1.5-3.4 \mathrm{~mm}$ ) distally. The median degree of angulation of the parent artery was $95^{\circ}$ (range, $10^{\circ}-170^{\circ}$ ). In 1 case, concomitant coils were used to pack the aneurysm because of its multilobulated morphology. In-stent angioplasty after flow-diverter deployment was performed in 1 patient with a dissecting MCA aneurysm and distal stenosis of the parent artery. In 2 cases, a mild $(<50 \%)$ stenosis of the FRED Jr after deployment was detected without the need for in-stent angioplasty. In 22/47 (47\%) aneurysms, an immediate impact on the degree of stasis (OKM grading scale) could be observed on angiography at the end of the endovascular procedure, and the angiographic degree of filling (OKM grading scale) was changed immediately in $11 / 47$ cases $(23 \%)$.

\section{Clinical Outcome and Procedure-Related Complications}

The primary safety end point could be observed in 39/42 (93\%) treated patients. One major stroke occurred in a patient with an atherosclerotic fusiform M1 aneurysm. After extubation, the patient had a hemiparesis. Immediate DSA control showed 
the stent in place with perfusion of all MCA branches. The MR imaging control showed watershed infarctions. The patient was discharged with an mRS 3 and recovered to mRS 2 at 3 months after treatment.

A minor stroke developed in a patient with an A1/A2 aneurysm. This patient woke up with a transient hemiparesis. Immediate MR imaging control showed an embolic shower in the ACA territory. The patient was discharged with an mRS 1 and recovered to mRS 0 at 3 months after treatment. Another patient with an MCA bifurcation aneurysm experienced transient ischemic symptoms (slight hemiparesis) 2 hours after FRED Jr placement, induced by an occlusion of the inferior MCA trunk on DSA. Complete resolution of symptoms was observed within 1 hour after intravenous tirofiban injection, with complete reopening of the trunk on control DSA.

Diminished flow in the adjacent vessels was detected within 30 minutes after deployment in a patient with a pericallosal aneurysm. After intravenous tirofiban injection, the flow changed to normal within 10 minutes and the patient did not show any neurologic deficit after extubation. The same patient presented, after normal findings on 3-month follow-up MR imaging, with multiple enhancing brain lesions at 6-month follow-up MR imaging. The patient was never symptomatic, and after 1 month of steroids, the enhancing lesions had disappeared completely. Another patient with a giant MCA aneurysm experienced an upper trunk MCA occlusion immediately after deployment. After intravenous tirofiban, the upper trunk reopened, and the patient was asymptomatic after extubation.

There was no statistically significant association between any pretreatment patient or aneurysm characteristic and the occurrence of these procedure-related complications.

\section{Follow-Up}

Complete angiographic (DSA or FPCT) and clinical follow-up was performed after a median of 1 month in $41 / 47$ (87\%) aneurysms, after a median of 6 months in 27/47 (57\%) aneurysms, and after a median of 12 months in 11/47 (23\%) aneurysms. Seventy-one percent of patients (30/42) had at least 1 DSA examination at follow-up. At 1-month follow-up, 6/41 (15\%) aneurysms showed complete occlusion (OKM D), and 21/41 (51\%) aneurysms, a near-complete occlusion (OKM C). At 6-month follow-up, in 19/27 (70\%) aneurysms, complete occlusion was observed (OKM D) and near-complete aneurysm occlusion was seen in $2 / 27$ (7\%). A complete filling was not detected in any of the followed aneurysms at 6 months. At 12-month follow-up, 8/11 (73\%) aneurysms were still completely occluded (OKM D), while 3/11 (27\%) aneurysms remained at near-complete occlusion (OKM C). Regardless of the follow-up timing, the primary end point for efficacy was reached in 32/41 (78\%) aneurysms with any follow-up.

No cases of in-stent stenosis, in-stent thrombosis, or migration of the FRED Jr implant were observed on follow-up DSA or FPCT. So far, no retreatment has been performed.

The performed $\chi^{2}$ and Kruskal-Wallis $\mathrm{H}$ tests showed no statistically significant differences among the different occlusion grades at 1, 6, or 12 months for any pretreatment patient or aneurysm characteristics.

\section{DISCUSSION}

In this clinical multicenter observational study, the FRED Jr device was assessed for the treatment of intracranial aneurysms in small arteries. While conventional microsurgical clipping or coiling with possible ballooning or stent placement remains the treatment of choice, few studies in the past have investigated the use of flow diverters in small vessels. ${ }^{11-16}$ This new generation of intracranial flow diverters dedicated to vessels of $\leq 3 \mathrm{~mm}$ may provide a promising alternative for the safe and effective treatment of these challenging aneurysms. In this series, all treated aneurysms were completely covered by the flow diverter at postprocedural follow-up. The primary end point for clinical safety (ie, absence of mortality and stroke [major or minor] or transient ischemic attack) was achieved in 39/42 (93\%) patients treated with the FRED Jr device. These findings are comparable with those in previous studies that focused on distal-circulation aneurysms treated with various intracranial flow diverters (in most cases the Pipeline Embolization Device), with up to $17.6 \%$ transient neurologic deficits, up to $10.7 \%$ permanent neurologic deficits, and no mortality. ${ }^{11-16}$

\section{Procedural Success}

In the present study, successful deployment of the FRED Jr device could be achieved in all cases. In 2 cases, a longer version of the FRED Jr was implanted because foreshortening of the initial FRED Jr was too pronounced, especially at the base of the aneurysm. Insufficient opening $(>50 \%)$ of the FRED Jr, which has been reported for other available flow diverters in up to $10 \%$ of cases, did not occur with the FRED Jr. ${ }^{18,19}$ Unsheathing and release of the FRED Jr was performed slowly for several minutes in a controlled fashion by retracting the delivery microcatheter only, to facilitate correct expansion and complete deployment of the FRED Jr. The so-called push/pull technique was usually not required. Should incomplete opening occur, despite these precautions, a complete retrieval of the FRED Jr device should be performed by simply resheathing it into the delivery microcatheter. In previous case series, delayed retraction of the flow diverter occurred, but this was not found in our series. ${ }^{1,19}$ Furthermore, on follow-up, no in-stent stenosis or changes in stent morphology such as "fish mouth" (ie, inward crimping of 1 or both ends of flow diverter) or "foreshortening" phenomena, which were described in a series by Kocer et $\mathrm{al}^{4}$ with the first version of FRED, were observed.

\section{Angiographic Outcome}

Occlusion results for the FRED Jr during early follow-up were promising. Immediately after FRED Jr deployment, a change in the degree of contrast stasis inside the aneurysm was noted in $>47 \%$ of cases, similar to results of the "regular" FRED. ${ }^{5}$ After 6 months, complete aneurysm occlusion, defined as an OKM grade of D, could be observed in 19/27 (70\%) cases, which, on the Raymond and Roy scale, would correspond to grade $\mathrm{I}^{20}$

Our efficacy rate was in line with the complete occlusion rate at $6-12$ months of $33 \%-79 \%$ seen in previous studies, which had focused on distal circulation aneurysms with various intracranial flow diverters (in most cases the Pipeline Embolization Device was used). ${ }^{11-14,16}$

AJNR Am J Neuroradiol 38:1959-65 Oct 2017 www.ajnr.org 


\section{Potential Advantages}

Advantages of the recently introduced FRED Jr may include the following: 1) enhanced outward stability of the stent toward the wall of the parent vessel due to the design (dual-layer) of the FRED Jr device and long sizes (available up to $41 \mathrm{~mm}$ ), which provide a scaffolding effect. Most important, a single device can be used to achieve aneurysm occlusion in a single treatment session, while previously, the treatment of fusiform or giant aneurysms may have required telescoping implantation of $>1$ flow diverter or 2 sequential procedures (scaffolding stent followed by flowdiverter implantation). 2) The lower number of wires (16 wires in the outer stent compared with 48 wires in the Silk or Pipeline device, for example) may result in lower friction within the delivery microcatheter, allowing a smoother deployment of longer stents. 3) Stent opening will be more reliable because radial force vectors of the inner and outer stent will add up. This feature is especially critical when deployment includes vessels with $>90^{\circ}$ angulation. 4) Laminar blood flow might be improved by the dual-layer design and higher pore attenuation. Compared with the 48 wires of the Pipeline and Silk, the FRED Jr device consists of 16 outer nitinol wires and 36 inner nitinol wires with 2 tantalum integration wires. 5) The short inner stent will result in lower vessel wall coverage in the longitudinal direction (shortest, $8 \mathrm{~mm}$, available on the market). The inner stent is designed to limit the working layer to the neck of the aneurysm and to spare adjacent branches, while maintaining the patency of these vessels. 6) The delivery microcatheter, Headway 21, is the smallest available delivery system on the market, with an outer distal diameter of $2 \mathrm{~F}$ compared with Vaso 21 (Balt Extrusion) (outer distal diameter, $2.4 \mathrm{~F}$ ) for Silk, and Marksman (outer distal diameter, 2.8F) for Pipeline. 7) The delivery wire always stays inside the flow diverter. Therefore, the risk of vessel perforation, especially in small vessels, might be lower.

The main differences of the FRED Jr compared with the FRED are the following: 1 ) the dual-layer design of FRED Jr consisting of $16+36$ wires instead of $16+48$ wires for the FRED. This resulted in a lower metal coverage of the vessel wall with the FRED Jr (approximately 30\% versus approximately 35\%-40\% with FRED). 2) The delivery wire system of the FRED Jr has no distal tip. 3) For FRED Jr delivery, a 0.021 -inch microcatheter is adequate, whereas the FRED requires a 0.027 -inch microcatheter.

\section{Clinical Outcome and Complications}

Overall, the primary safety end point could not be achieved in 3 patients $(7 \%)$. However, only 1 patient had resulting permanent neurologic deficits (major stroke, 2\%). The selected FRED Jr, in this case with an atherosclerotic fusiform M1 aneurysm, seemed too long and compromised the perfusion in $1 \mathrm{M} 2$ branch. MR imaging control showed watershed infarctions. The patient was discharged with a hemiparesis and recovered to mRS 2 at 3 months after treatment. The minor stroke occurred in a patient with an A1/A2 aneurysm. The immediate MR imaging control showed an embolic shower in the ACA territory, which was probably because several attempts were needed to deploy the FRED Jr in a satisfactory position. The remaining symptomatic patient with a TIA had an occlusion of the lower MCA trunk, which is probably related to the Coandă effect (see below). Asymptomatic thrombosis of covered side branches was detected within 30 minutes after deployment in a patient with a pericallosal aneurysm and in another patient with a giant MCA bifurcation aneurysm. After intravenous tirofiban injection, the thrombosis resolved completely within 20 minutes. These 2 side-branch occlusions are likely device-related, such as incomplete wall apposition with emerging thrombus formation. However, the possibility of insufficient opening of the FRED Jr was ruled out by FPCT, and both patients had a good response to antiplatelet therapy in prior tests.

Immediate thrombosis of a covered side branch can be explained by the Coandă effect, a phenomenon in which a jet flow attaches itself to a nearby surface and remains attached even when the surface curves away from the initial jet direction. ${ }^{21}$ The patient with the pericallosal aneurysm presented at follow-up with multiple enhancing brain lesions, similar to those described by Cruz et $\mathrm{al}^{22}$ suggesting a foreign body reaction, potentially caused by shedding of the hydrophilic coating. The patient never developed any symptoms, and after 1 month of steroids, the enhancing lesions had disappeared.

Three of 5 complications occurred in patients with MCA aneurysms, which are known to pose a higher risk of thromboembolic complications. ${ }^{16,18}$

\section{Limitations}

We conducted a multicenter, retrospective, observational study; therefore, there was inherent selection bias associated with it. The overall number of patients was small, and no statistical significance was discovered in univariate or multivariate analyses, likely owing to the lack of power. Moreover, the relatively recent adoption of FRED Jr in clinical use and the short follow-up period in our study imply that the durability of the treatment and longterm consequences with FRED Jr remain to be determined. To the best of our knowledge, however, this is the largest study of aneurysms located on small vessels treated with flow diverters, and our data demonstrate that the FRED Jr is a safe and effective form of treatment for aneurysms located on small arteries that are challenging for both conventional microsurgical and endovascular techniques.

\section{CONCLUSIONS}

In this first observational study of the FRED Jr for the treatment of distally located intracranial aneurysms, a high degree of safety and a high rate of complete aneurysm occlusion were observed. Longterm durability and safety should be proved by larger series. Our results support the notion that the use of intracranial micro-flow diverters, such as reported herein, may increase the armamentarium of procedural techniques for the neurointerventionalist, especially for targeting distally located aneurysms in which parent vessel diameters are $\leq 3 \mathrm{~mm}$.

\section{ACKNOWLEDGMENTS}

The authors wish to thank Susanne Bonekamp and Sedat Giray Kandemirli for assistance with manuscript preparation.

Disclosures: Markus A. Möhlenbruch—UNRELATED: Payment for Lectures Including Service on Speakers Bureaus: Codman, Medtronic, MicroVention, phenox, Stryker. Monika Killer-Oberpfalzer-UNRELATED: Board Membership: research grant, MicroVention/Terumo. * Civan Islak-UNRELATED: Consultancy: Covidien; Patents 
(Planned, Pending or Issued): 4D detachable embolic coil (US Pub No: US0327868A1); Stock/Stock Options: NDI Inc, Comments: 10\%. Martin Bendszus-UNRELATED: Board Membership: DSMB for Vascular Dynamics; Consultancy: Codman, Roche, Guerbet, Boehringer Ingelheim; Grants/Grants Pending: Deutsche Forschungsgemeinschaft, Dietmar Hopp Foundation, Novartis, Siemens, Guerbet, Stryker, Covidien*; Payment for Lectures Including Service on Speakers Bureaus: Novartis, Roche, Guerbet, Teva, Bayer HealthCare Pharmaceuticals, Codman. Saruhan Cekirge-UNRELATED: Consultancy: Medtronic; Consulting Fee or Honorarium: MicroVention. Isil Saatci-UNRELATED: Consultancy: Medtronic. Naci KocerUNRELATED: Consultancy: MicroVention*; Payment for Lectures Including Service on Speakers Bureaus: MicroVention, Comments: I also have a proctoring agreement with MicroVention. * Money paid to the institution.

\section{REFERENCES}

1. Brinjikji W, Murad MH, Lanzino G, et al. Endovascular treatment of intracranial aneurysms with flow diverters: a meta-analysis. Stroke 2013;44:442-47 CrossRef Medline

2. Cebral JR, Mut F, Raschi M, et al. Analysis of hemodynamics and aneurysm occlusion after flow-diverting treatment in rabbit models. AJNR Am J Neuroradiol 2014;35:1567-73 CrossRef Medline

3. Kallmes DF, Ding YH, Dai D, et al. A second-generation, endoluminal, flow-disrupting device for treatment of saccular aneurysms. AJNR Am J Neuroradiol 2009;30:1153-58 CrossRef Medline

4. Kocer N, Islak C, Kizilkilic O, et al. Flow Re-direction Endoluminal Device in treatment of cerebral aneurysms: initial experience with short-term follow-up results. J Neurosurg 2014;120:1158-71 CrossRef Medline

5. Möhlenbruch MA, Herweh C, Jestaedt L, et al. The FRED flow-diverter stent for intracranial aneurysms: clinical study to assess safety and efficacy. AJNR Am J Neuroradiol 2015;36:1155-61 CrossRef Medline

6. Alherz AI, Tanweer O, Flamini V. A numerical framework for the mechanical analysis of dual-layer stents in intracranial aneurysm treatment. J Biomech 2016;49:2420-27 CrossRef Medline

7. Briganti F, Leone G, Ugga L, et al. Safety and efficacy of flow redirection endoluminal device (FRED) in the treatment of cerebral aneurysms: a single center experience. Acta Neurochir (Wien) 2016; 158:1745-55 CrossRef Medline

8. Drescher F, Weber W, Berlis A, et al. Treatment of intra- and extracranial aneurysms using the Flow-Redirection Endoluminal Device: multicenter experience and follow-up results. AJNR Am J Neuroradiol 2017;38:105-12 CrossRef Medline

9. Luecking H, Engelhorn T, Lang S, et al. FRED flow diverter: a study on safety and efficacy in a consecutive group of 50 patients. AJNR Am J Neuroradiol 2017;38:596-602 CrossRef Medline

10. Brouillard AM, Sun X, Siddiqui AH, et al. The use of flow diversion for the treatment of intracranial aneurysms: expansion of indications. Cureus 2016;8:e472 CrossRef Medline

11. Pistocchi S, Blanc R, Bartolini B, et al. Flow diverters at and beyond the level of the circle of Willis for the treatment of intracranial aneurysms. Stroke 2012;43:1032-38 CrossRef Medline

12. Martin AR, Cruz JP, O'Kelly C, et al. Small pipes: preliminary experience with 3-mm or smaller Pipeline flow-diverting stents for aneurysm repair prior to regulatory approval. $A J N R$ Am J Neuroradiol 2015;36:557-61 CrossRef Medline

13. Lin N, Lanzino G, Lopes DK, et al. Treatment of distal anterior circulation aneurysms with the Pipeline Embolization Device: a US multicenter experience. Neurosurgery 2016;79:14-22 CrossRef Medline

14. Martínez-Galdámez M, Romance A, Vega P, et al. Pipeline endovascular device for the treatment of intracranial aneurysms at the level of the circle of Willis and beyond: multicenter experience. J Neurointerv Surg 2015;7:816-23 CrossRef Medline

15. Puri AS, Massari F, Asai T, et al. Safety, efficacy, and short-term follow-up of the use of Pipeline Embolization Device in small $(<2.5$ $\mathrm{mm}$ ) cerebral vessels for aneurysm treatment: single institution experience. Neuroradiology 2016;58:267-75 CrossRef Medline

16. Gawlitza M, Januel AC, Tall P, et al. Flow diversion treatment of complex bifurcation aneurysms beyond the circle of Willis: a single-center series with special emphasis on covered cortical branches and perforating arteries. J Neurointerv Surg 2016;8:481-87 CrossRef Medline

17. O'Kelly CJ, Krings T, Fiorella D, et al. A novel grading scale for the angiographic assessment of intracranial aneurysms treated using flow diverting stents. Interv Neuroradiol 2010;16:133-37 CrossRef Medline

18. Brinjikji W, Lanzino G, Cloft HJ, et al. Risk factors for ischemic complications following Pipeline Embolization Device treatment of intracranial aneurysms: results from the IntrePED Study. AJNR Am J Neuroradiol 2016;37:1673-78 CrossRef Medline

19. Lubicz B, Collignon L, Raphaeli G, et al. Flow-diverter stent for the endovascular treatment of intracranial aneurysms: a prospective study in 29 patients with 34 aneurysms. Stroke 2010;41:2247-53 CrossRef Medline

20. Raymond J, Guilbert F, Weill A, et al. Long-term angiographic recurrences after selective endovascular treatment of aneurysms with detachable coils. Stroke 2003;34:1398-403 CrossRef Medline

21. Kocer N. Giant Intracranial Aneurysms: A Case-Based Atlas of Imaging and Treatment. New York: Springer; 2016:68-70

22. Cruz JP, Marotta T, O'Kelly C, et al. Enhancing brain lesions after endovascular treatment of aneurysms. AJNR Am J Neuroradiol 2014; 35:1954-58 CrossRef Medline 